\title{
A Study on the Kinetic Behavior of Listeria monocytogenes in Ice Cream Stored Under Static and Dynamic Chilling and Freezing Conditions
}

\author{
M. Gougouli, ${ }^{*}$ A. S. Angelidis, $\dagger$ and K. Koutsoumanis ${ }^{* 1}$ \\ *Laboratory of Food Hygiene and Microbiology, Department of Food Science and Technology, Faculty of Agriculture, and \\ †Laboratory of Milk Hygiene and Technology, Department of Food Hygiene and Technology, Faculty of Veterinary Medicine, \\ Aristotle University of Thessaloniki, Thessaloniki 54124 Greece
}

\begin{abstract}
The kinetic behavior of Listeria monocytogenes in 2 commercial ice cream products (A and $\mathrm{B}$ ) that were inoculated and stored under static chilling $\left(4\right.$ to $\left.16^{\circ} \mathrm{C}\right)$, static freezing $\left(-5\right.$ to $\left.-33^{\circ} \mathrm{C}\right)$, dynamic chilling, and dynamic chilling-freezing conditions was studied, simulating conditions of the aging process and of normal or abuse conditions during distribution and storage. The ice cream products $\mathrm{A}$ and $\mathrm{B}$ had different compositions but similar $\mathrm{pH}$ (6.50 and 6.67, respectively) and water activity ( 0.957 and 0.965 , respectively) values. For both chilling and freezing conditions, the kinetic behavior of the pathogen was similar in the 2 products, indicating that the $\mathrm{pH}$ and water activity, together with temperature, were the main factors controlling growth. Under chilling conditions, L. monocytogenes grew well at all temperatures tested. Under freezing conditions, no significant changes in the population of the pathogen were observed throughout a 90-d storage period for either of the inoculum levels tested $\left(10^{3}\right.$ and $\left.10^{6} \mathrm{cfu} / \mathrm{g}\right)$. Growth data from chilled storage conditions were fitted to a mathematical model, and the calculated maximum specific growth rate was modeled as a function of temperature by using a square root model. The model was further validated under dynamic chilling and dynamic chilling-freezing conditions by using 4 different storage temperature scenarios. Under dynamic chilling conditions, the model accurately predicted the growth of the pathogen in both products, with $99.5 \%$ of the predictions lying within the $\pm 20 \%$ relative error zone. The results from the chilling-freezing storage experiments showed that the pathogen was able to initiate growth within a very short time after a temperature upshift from freezing to chilling temperatures. This indicates that the freezing conditions did not cause a severe stress in L. monocytogenes cells capable of leading to a significant "additional" lag phase during the subsequent
\end{abstract}

Received April 4, 2007.

Accepted October 15, 2007.

${ }^{1}$ Corresponding author: kkoutsou@agro.auth.gr growth of the pathogen at chilling conditions. As a result, the application of the model at chilling-freezing conditions resulted in satisfactory performance, with $98.3 \%$ of the predictions lying within the $\pm 20 \%$ relative error zone. The present study provides useful data for understanding the behavior of $L$. monocytogenes in ice cream stored under single or combined chilling and freezing conditions. In addition, the study showed that such data can be expressed in quantitative terms via the application of mathematical models, which can be used by the dairy industry as effective tools for predicting the behavior of the pathogen during the manufacture, distribution, and storage of ice cream products. Key words: kinetic behavior, Listeria monocytogenes, ice cream

\section{INTRODUCTION}

Listeria monocytogenes is a gram-positive, psychrotolerant foodborne pathogen that is widely distributed in nature and is the causative agent of listeriosis, a serious invasive disease in both domestic animals and humans (Schlech et al., 1983; Farber and Peterkin, 1991; Low and Donachie, 1997). Listeria monocytogenes has been repeatedly isolated from various sources within the environment of dairy manufacturing plants (Walker et al., 1991; Cotton and White, 1992; Miettinen et al., 1999). Although no ice cream-related listeriosis outbreaks have been reported to date, $3 \%$ of the ice cream samples and $8.5 \%$ of novelty ice cream samples examined in the United States during 1986 and 1987 were found to be positive for L. monocytogenes, and several $L$. monocytogenes-related voluntary class I recalls of ice cream products were issued in subsequent years (Ryser, 1999). The reported prevalence estimates for $L$. monocytogenes in ice cream from other countries ranges between 0 and 20\% (Greenwood et al., 1991; $\mathrm{Ng}$ and Seah, 1995; Kozak et al., 1996; Baek et al., 2000; Cordano and Rocourt, 2001; Pak et al., 2002; Molla et al., 2004; Meldrum et al., 2005; El-Sharef et al., 2006; Kiss et al., 2006). Previous studies have adequately documented the resistance of $L$. monocytogenes in ice 
cream during frozen storage (Palumbo and Williams, 1991; Dean and Zottola, 1996). Contaminated ice cream may therefore constitute a health hazard for consumers who are at high risk for listeriosis.

The control of $L$. monocytogenes in ice cream products via the Hazard Analysis Critical Control Point system is focused on the selection of good-quality raw milk and stringent control of the processing, packaging, distribution, and storage conditions. Although the pathogen is effectively controlled during the pasteurization process of the ice cream mix, its presence in the finished product is most likely the result of postpasteurization contamination from sources in the plant environment (Kozak et al., 1996). Considering the various postpasteurization steps involved in ice cream production, distribution, and storage, and given that $L$. monocytogenes does not grow at temperatures below freezing, the critical stages in a batch of ice cream that may be contaminated after pasteurization would be 1 ) the stage of the aging process during which the ice cream mix is stored for a variable time period at refrigeration temperatures (typically 0 to $5^{\circ} \mathrm{C}$ ), and 2 ) the stages of transportation and storage of the finished product during which there is a potential for severe temperature abuse (e.g., during unloading of ice cream products from trucks).

An alternative approach to traditional methods of safety assurance is to use quantitative microbiological tools. Quantitative microbiology seems as an attractive and pertinent tool for food safety assurance, especially when the new microbiological safety criteria outlined in the European Union Regulation 2073/2005 are considered (European Commission, 2005). Regulation 2073/2005 categorizes ready-to-eat (RTE) foods into those that are able to support the growth of L. monocytogenes and those that are not. For RTE foods that are able to support the growth of $L$. monocytogenes, the new Regulation demands the absence of the pathogen (in $25 \mathrm{~g}$ ) "before the food has left the immediate control of the food business operator, who has produced it," but allows for up to $100 \mathrm{cfu} / \mathrm{g}$ for "products placed on the market during their shelf-life." The $100 \mathrm{cfu} / \mathrm{g}$ limit also applies throughout the shelf life of marketed RTE foods unable to support $L$. monocytogenes growth. It would therefore be of interest for ice cream manufacturers to be able to predict the potential or the extent of growth of $L$. monocytogenes in their product(s) under different conditions. Such conditions may include differences in the formulation of the product that may affect product parameters that influence microbial growth $[\mathrm{pH}$ and water $\left.\operatorname{activity}\left(\mathbf{a}_{\mathbf{w}}\right)\right]$, as well as differences in the temperatures to which these products are exposed at various steps during their manufacture, transportation, and storage.
During the last decade, a large number of mathematical models describing the effect of temperature on the kinetic parameters of $L$. monocytogenes have been published (Farber et al., 1996; George et al., 1996; Fernández et al., 1997; McClure et al., 1997; Buchanan and Phillips, 2000), and some of them are targeted to dairy products (Murphy et al., 1996; Alavi et al., 1999; Augustin et al., 2005; Xanthiakos et al., 2006). The majority of these models have been developed by using data obtained from experiments conducted under well-defined and controlled laboratory settings with microbiological media. Therefore, it is no surprise that validation studies have shown that the predictions of these models are not necessarily valid for actual foods (Pin et al., 1999; Xanthiakos et al., 2006). This may be because such models have focused only on the effect of environmental conditions (temperature, $\mathrm{pH}, \mathrm{a}_{\mathrm{w}}$, atmosphere) on microbial growth and have not taken into account other, often underestimated, factors such as the food composition or the microbial competition, which may significantly influence microbial growth (Pin et al., 1999). For example, Xanthiakos et al. (2006) reported that the growth of $L$. monocytogenes in pasteurized milk was significantly slower than that predicted by 4 published models developed from experiments in laboratory media. The authors attributed this observation to the fact that the models developed with laboratory media did not take into account the presence of natural antimicrobial compounds in the milk, such as lactoperoxidase (Stopforth et al., 2005), and the presence of competitive microflora that may inhibit the growth of the pathogen. Furthermore, most of the existing models have been developed and validated under static temperature conditions. In such models, an understanding of the effect of dynamic conditions on bacterial growth is still missing.

The objectives of the present study were 1) to study the kinetic behavior of $L$. monocytogenes in ice cream stored under chilling and freezing conditions, 2) to develop a product-targeted mathematical model for the effect of temperature on the behavior of $L$. monocytogenes in ice cream, and 3) to evaluate the ability of the developed model to predict the behavior of the pathogen under a) different chilling (static or dynamic) conditions that may occur during the aging stage of the ice cream mix and b) different chilling-freezing conditions that may occur during the transportation, distribution, and storage of ice cream.

\section{MATERIALS AND METHODS}

\section{Bacterial Strain, Inoculation of Ice Cream, and Microbiological Analysis}

Listeria monocytogenes Scott A was used throughout the study. Stock cultures were kept frozen $\left(-30^{\circ} \mathrm{C}\right)$ in 
tryptic soy broth (TSB; Merck, Darmstadt, Germany) supplemented with $20 \%$ glycerol and were regenerated by transferring $50 \mu \mathrm{L}$ into $10 \mathrm{~mL}$ of TSB and incubating at $30^{\circ} \mathrm{C}$ for $24 \mathrm{~h}$. Aliquots $(0.1 \mathrm{~mL})$ of activated cultures were transferred to $10 \mathrm{~mL}$ of TSB, incubated at $30^{\circ} \mathrm{C}$ for $24 \mathrm{~h}$ to reach the late stationary phase, and then centrifuged $(4,629 \times \mathrm{g}$ for $15 \mathrm{~min})$ in a refrigerated centrifuge (model PK120R, ThermoElectron Corporation, Waltham, MA). The pellet was washed with 10 $\mathrm{mL}$ of quarter-strength Ringer's solution (Merck), centrifuged as described previously, and resuspended in $10 \mathrm{~mL}$ of fresh Ringer's solution.

Two commercial ice cream products (A and B) were tested during the study. The ingredients of ice cream product A were milk cream, sugar, glucose syrup, NDM, whey powder, caramelized sugar syrup, stabilizersemulsifiers (E-440, E-466, E-471), egg yolk powder, and flavoring. Ice cream product B consisted of sugar, chocolate powder (sugar, cocoa), glucose syrup, vegetable fat, NDM, whey powder, dextrose, stabilizers-emulsifiers (E-446, E-471), egg yolk powder, colorant (E-150d), vanillin, and flavoring.

For each product, the $\mathrm{a}_{\mathrm{w}}$ and $\mathrm{pH}$ values of both the ice cream mix (before aging) and of the melted ice cream (final product) were determined at $25^{\circ} \mathrm{C}$ by using an Aqualab Series 3 water activity determination device (Decagon Devices Inc., Pullman, WA) and at $22^{\circ} \mathrm{C}$ by using a pH meter ( $\mathrm{pH} 211$ Microprocessor, Hanna Instruments BV, Ijsselstein, the Netherlands), respectively. The $\mathrm{pH}$ and $\mathrm{a}_{\mathrm{w}}$ of melted ice cream were 6.50 and 0.957 for product $A$ and 6.67 and 0.965 for product $\mathrm{B}$, respectively. Similar $\mathrm{pH}$ and $\mathrm{a}_{\mathrm{w}}$ values were found for the respective ice cream mixes. Ice cream samples (500-mL packages) were transferred from their production site to the laboratory under freezing conditions $\left(-18^{\circ} \mathrm{C}\right)$ within $24 \mathrm{~h}$. Prior to their inoculation, samples were stored at $0^{\circ} \mathrm{C}$ for $6 \mathrm{~h}$. Melted ice cream was then transferred aseptically to sterile stomacher bags and inoculated with appropriately diluted and washed $L$. monocytogenes culture as described above. The inoculated samples were subsequently homogenized by mixing for 90 s with a Bag-Mixer 400 stomacher (Interscience, St. Nom, France) to obtain a target inoculum of $10^{3}$ to $10^{6} \mathrm{cfu} / \mathrm{g}$. Homogenized mixtures were carefully poured into their original containers and stored under different conditions.

Inoculated packages were stored under controlled isothermal chilling $\left(4,8,12\right.$, and $\left.16^{\circ} \mathrm{C}\right)$, freezing $(-5,-15$, -23 , and $-33^{\circ} \mathrm{C}$ ), or dynamic chilling and dynamic chilling-freezing conditions in high-precision $\left( \pm 0.2^{\circ} \mathrm{C}\right)$, lowtemperature incubators (model MIR 153, Sanyo Electric Co., Ora-Gun, Gunma, Japan). The temperature in the center of the sample packages was monitored during storage by using electronic temperature-monitoring devices (Cox Tracer, Cox Technologies, Belmont, NC). Duplicate aliquots from samples at each storage temperature condition were taken at appropriate time intervals to allow for efficient kinetic analysis of microbial growth. For the enumeration of $L$. monocytogenes, 0.1$\mathrm{mL}$ volumes of appropriate serial dilutions of ice cream samples were spread on the surface of PALCAM agar plates (Merck) and incubated at $30^{\circ} \mathrm{C}$ for $48 \mathrm{~h}$. Uninoculated samples were also stored under the same conditions and analyzed for the presence of Listeria spp. The pathogen was not found in any of the uninoculated samples throughout the storage period.

\section{Data Analysis}

For experiments at isothermal conditions, 4 ice cream samples (2 independent experiments with 2 replications for each experiment) were analyzed for each product and each temperature condition. Data were evaluated by ANOVA with the GLM procedure of the Minitab software package (Minitab Inc., State College, PA), and least squares means were separated by using the pairwise $t$-test. For experiments at dynamic temperature conditions, 2 samples from one experiment were analyzed for each product and each temperature profile.

\section{Description of the Applied Mathematical Model}

Listeria monocytogenes growth data (log $\mathrm{cfu} / \mathrm{g})$ in ice cream stored under isothermal chilling conditions were fitted to the model of Baranyi and Roberts (1994). The maximum specific growth rates $\left(\mu_{\max }\right)$ estimated at isothermal conditions were modeled as a function of storage temperature by using the square root model (Ratkowsky et al., 1982):

$$
\sqrt{\mu_{\max }}=b\left(T-T_{\min }\right)
$$

where $b$ is a constant, $T\left({ }^{\circ} \mathrm{C}\right)$ is temperature, and $T_{\min }$ is the theoretical minimum temperature of growth of the organism, estimated by extrapolation of the regression line to $\mu_{\max }=0$. Growth rates were fitted to equation [1] by using Microsoft Excel (Microsoft Corporation, Redmond, WA).

The prediction of growth under dynamic temperature was based on the time-temperature profile of ice cream, $T(t)$, in conjunction with the square root model (equation [1]) for the estimation of the "momentary" $\mu_{\max }$ and also on the model of Baranyi and Roberts (1994; equations [2] and [3]):

$$
\frac{d}{d t} x=\left\{b\left[T(t)-T_{\min }\right]\right\}^{2}\left(\frac{q}{q+1}\right)\left(1-\frac{x}{x_{\max }}\right) x, \text { and }
$$




$$
\frac{d}{d t} q=\left\{b\left[T(t)-T_{\min }\right]\right\}^{2} q
$$

where $t$ is time, $x$ is the concentration of the L. monocytogenes population (cfu/g) at time $t, x_{\max }$ is the maximum concentration of the population, and $q$ is a parameter that denotes the concentration of a substance critical to growth. The explicit form of equations [2] and [3] were used for the prediction at dynamic temperature conditions based on the "momentary" $\mu_{\max }$ corresponding to the temperature recorded by the data loggers with Microsoft Excel. The momentary $\mu_{\max }$ for $T \geq T_{\min }$ was calculated from equation [1], whereas for $T<T_{\min }$, $\mu_{\max }$ was assumed to be 0 based on the experimental results obtained under static freezing storage conditions.

\section{RESULTS AND DISCUSSION}

Representative curves of $L$. monocytogenes growth in ice cream products $\mathrm{A}\left(\mathrm{pH}: 6.50 ; \mathrm{a}_{\mathrm{w}}: 0.957\right)$ and $\mathrm{B}(\mathrm{pH}$ : $\left.6.67 ; \mathrm{a}_{\mathrm{w}}: 0.965\right)$ stored under isothermal temperature conditions from 4 to $16^{\circ} \mathrm{C}$ are shown in Figure 1. The results showed that $L$. monocytogenes was able to grow well in both products stored under the tested temperature range. The growth data were fitted to the primary model of Baranyi and Roberts (1994) to calculate the kinetic parameters, that is, the maximum specific growth rate $\left(\mu_{\max }\right)$, the lag phase $(\lambda)$, and the maximum population density $\left(x_{\max }\right)$. The $\mu_{\max }$ increased from $0.016 / \mathrm{h}$ (average value) at $4^{\circ} \mathrm{C}$ to $0.146 / \mathrm{h}$ at $16^{\circ} \mathrm{C}$ in product $\mathrm{A}$ and from $0.017 / \mathrm{h}$ at $4^{\circ} \mathrm{C}$ to $0.137 / \mathrm{h}$ at $16^{\circ} \mathrm{C}$ in product $\mathrm{B}$. For both products, the maximum population density was found to be unaffected by storage temperature $(P>0.05)$, having an average value of 9.02 and a standard deviation of $0.43 \mathrm{log} \mathrm{cfu} / \mathrm{g}$. The parameter $h_{0}$, related to the physiological state of the cells (Baranyi and Roberts, 1994), was calculated as the product of $\mu_{\max } \times \lambda$ based on the values of $\mu_{\max }$ and $\lambda$ observed under the tested isothermal conditions. As in the case of the maximum population density, the parameter $h_{0}$ was not found to be affected by storage temperature (average value of 2.08). This observation is in agreement with other studies suggesting that the physiological state of the cells should be constant at different storage temperatures when the preinoculation history of the culture is identical (Baranyi and Roberts, 1994; Baranyi et al., 1995; Pin et al., 2002). In general, despite the differences in their formulation, the growth of $L$. monocytogenes in the 2 ice cream products was not significantly different $(P>0.05)$. The specific growth rate observed in both products was further modeled as a function of temperature by using a square root-type model (Figure 2). The model satisfactorily described
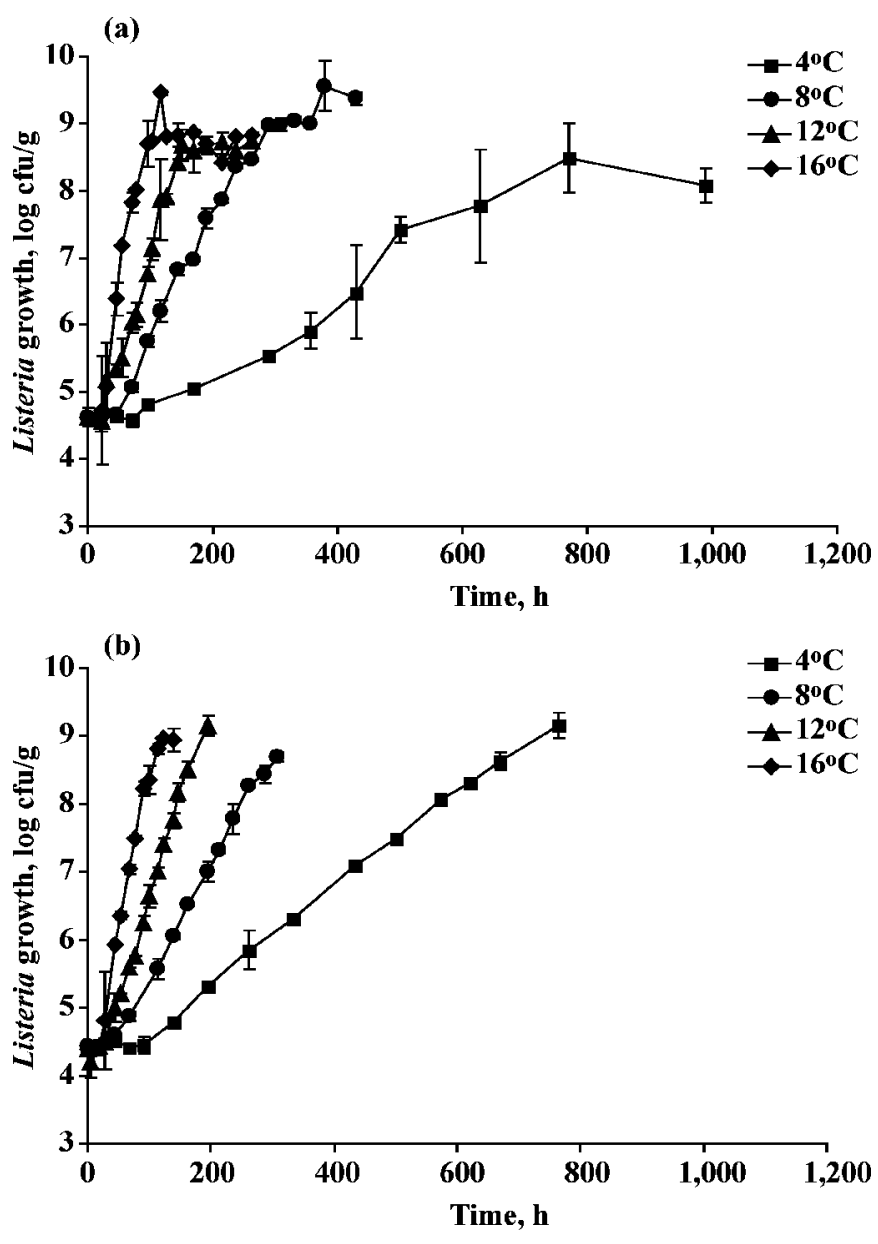

Figure 1. Growth curves of Listeria monocytogenes in ice cream products A (a) and B (b) under different isothermal storage temperatures. Each point is a mean of 4 values. Vertical bars indicate the standard deviation.

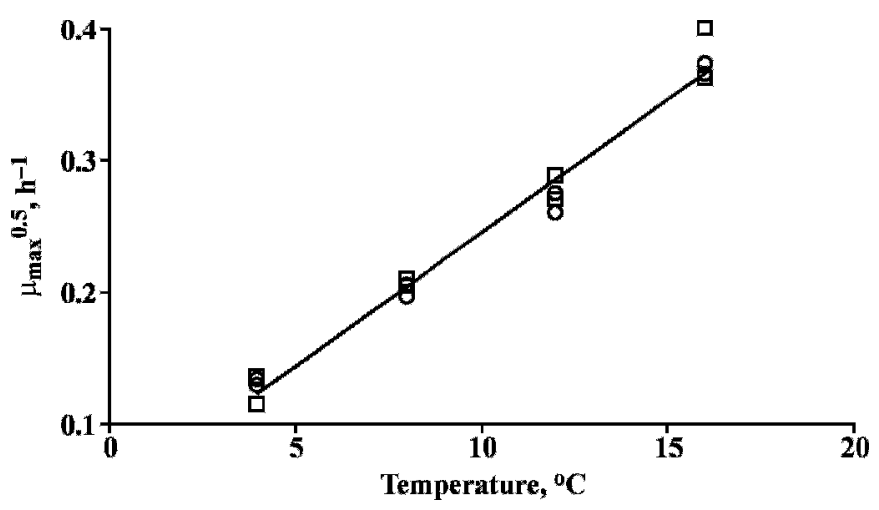

Figure 2. Square root model for the effect of chilling temperature on the maximum specific growth rate $\left(\mu_{\max }\right)$ of Listeria monocytogenes in 2 ice cream products ( $\square$ : product A; $\bigcirc$ : product B). Each point represents the mean of 2 replications from one experiment. 
Table 1. Parameters and statistics for the square root-type model for the effect of chilling temperature on the maximum specific growth rate $\left(\mu_{\max }\right)$ of Listeria monocytogenes in ice cream ${ }^{1}$

\begin{tabular}{lccc}
\hline Parameter $^{2}$ & Estimated value & Lower 95\% $\mathrm{CI}^{3}$ & Upper 95\% CI \\
\hline$b$ & 0.0203 & 0.0186 & 0.0219 \\
$T_{\min },{ }^{\circ} \mathrm{C}$ & -2.102 & -2.767 & -1.319 \\
\hline
\end{tabular}

${ }^{1}$ Maximum specific growth rates for both products A and B were used for the development of the model.

${ }^{2}$ For both parameters, $\mathrm{r}^{2}=0.980$.

${ }^{3} \mathrm{CI}=$ confidence interval.

the effect of temperature on L. monocytogenes growth (Table 1). The calculated value for the theoretical minimum temperature of growth $\left(T_{\min }\right)$ was $-2.1^{\circ} \mathrm{C}$. The estimated minimum temperature of growth $\left(T_{\min }\right)$ was similar to that reported in other studies on L. monocytogenes (Alavi et al., 1999; te Giffel and Zwietering, 1999; Augustin et al., 2005; Xanthiakos et al., 2006).

The developed model can be used by the dairy industry to control L. monocytogenes growth during ice cream production. Considering that under normal conditions, the aging process is the only postpasteurization stage within the ice cream production chain in which growth of the pathogen may occur, the developed model can be applied to predict the required time-temperature conditions that can ensure compliance with the new $L$. monocytogenes safety criteria (European Commission, 2005). Figure 3 shows the time-temperature conditions during the aging step that do not allow the pathogen to exceed the level of $100 \mathrm{cfu} / \mathrm{g}$ at the end of the aging process, assuming a maximum potential contamination of $1 \mathrm{cfu} / \mathrm{g}$ for the ice cream mix prior to the aging step. The dairy industry can then select the appropriate time and temperature conditions for the aging process that lead to the optimization of product quality and, at the

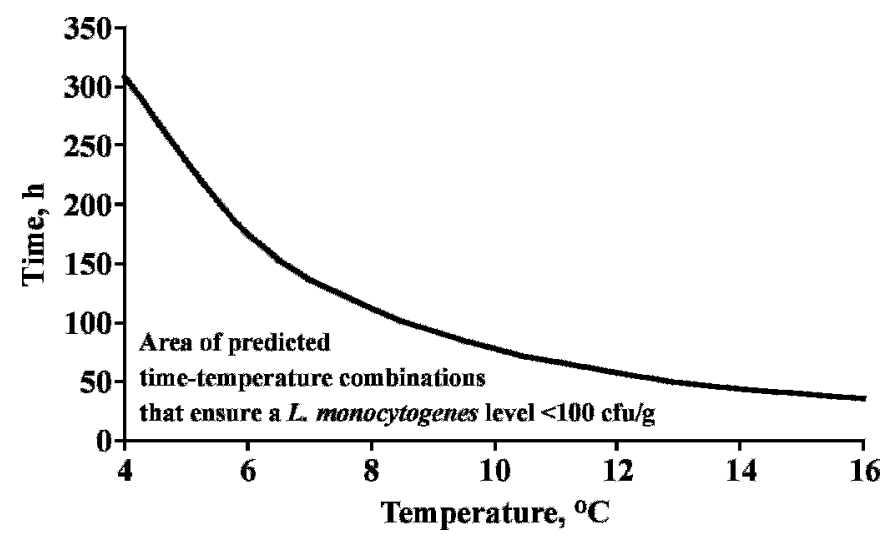

Figure 3. Predicted time-temperature conditions during the aging step that do not allow Listeria monocytogenes to exceed the level of $100 \mathrm{cfu} / \mathrm{g}$ at the end of the aging process, assuming a maximum potential contamination of $1 \mathrm{cfu} / \mathrm{g}$ for the ice cream mix prior to the aging step. same time, ensure compliance with the safety criteria. However, the model should be always used in combination with validation studies for comparing predictions with growth of the pathogen in the ice cream product of interest.

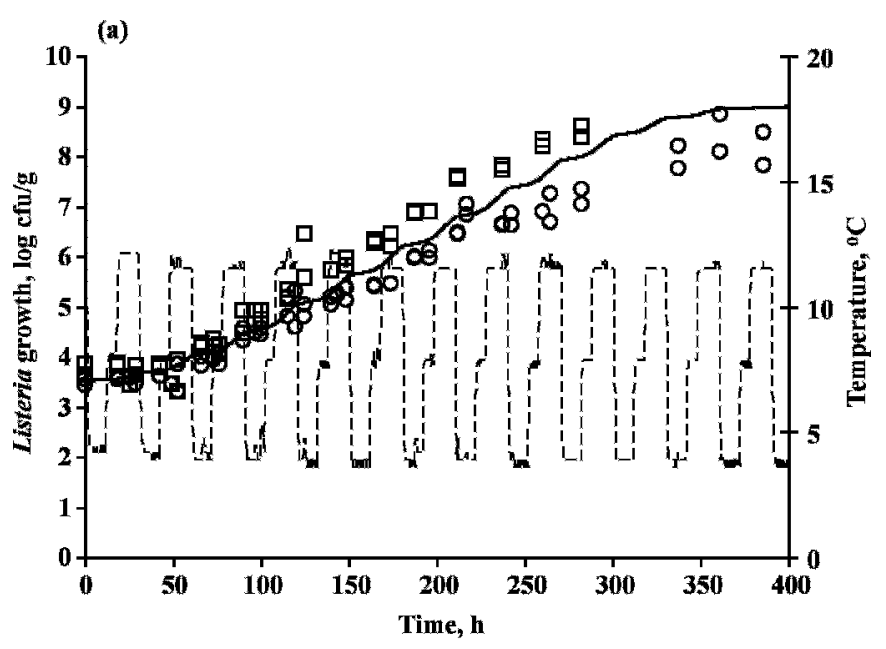

(b)

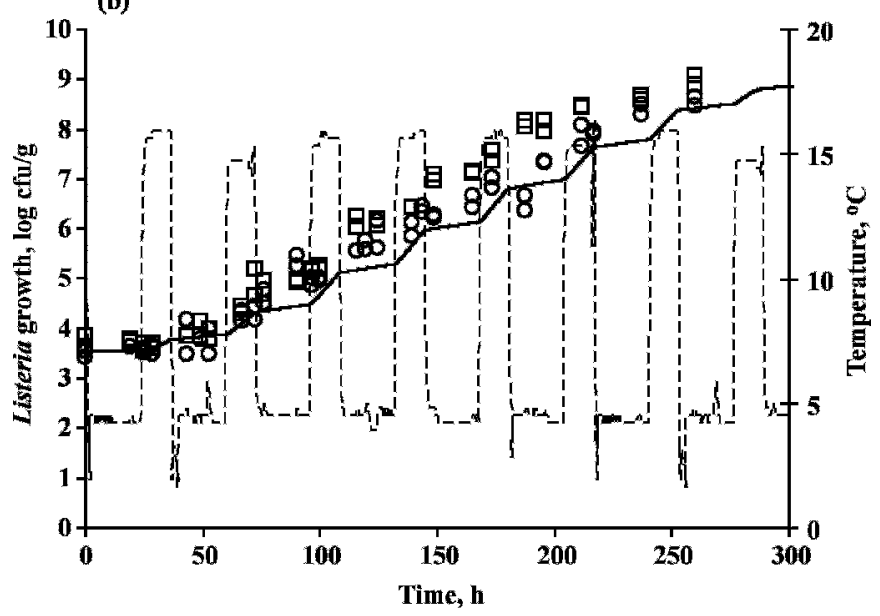

Figure 4. Comparison between the observed (points) and the predicted (lines) growth of Listeria monocytogenes in 2 ice cream products ( $\square$ : product $\mathrm{A}$; $\bigcirc$ : product $\mathrm{B}$ ) stored under periodically changing chilling conditions (a: $12 \mathrm{~h}$ at $4^{\circ} \mathrm{C}, 6 \mathrm{~h}$ at $8^{\circ} \mathrm{C}$, and $12 \mathrm{~h}$ at $12^{\circ} \mathrm{C}$; b: $24 \mathrm{~h}$ at $4^{\circ} \mathrm{C}$, and $6 \mathrm{~h}$ at $16^{\circ} \mathrm{C}$ ). Each point represents one replication from the same experiment. 


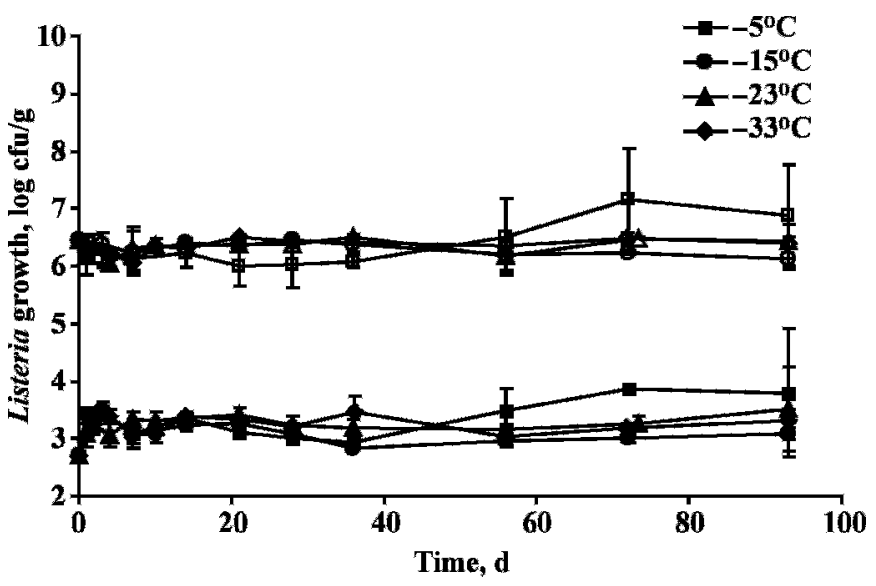

Figure 5. Survival of Listeria monocytogenes (open symbols: inoculation level of $10^{6} \mathrm{cfu} / \mathrm{g}$; solid symbols: inoculation level of $10^{3} \mathrm{cfu} / \mathrm{g}$ ) in ice cream (product A) stored under different isothermal freezing conditions. Each point is a mean of 4 values. Vertical bars indicate the standard deviation.

The developed model was also validated under dynamic chilling temperature conditions by using 2 periodically changing temperature profiles. The comparison between the predicted and observed growth of L. monocytogenes in ice cream stored under the 2 different dynamic temperature conditions is shown in Figure 4. For both temperature profiles tested, the model yielded satisfactory results, with $99.5 \%$ of the predictions lying within the $\pm 20 \%$ relative error (RE) zone (\%RE = $\left[\left(\mathrm{n}_{\text {observed }}-\mathrm{n}_{\text {predicted }}\right) / \mathrm{n}_{\text {observed }}\right] \times 100, \mathrm{n}$ in log cfu/g $)$, indicating that it can be used for monitoring the behavior of the pathogen during the aging of ice cream under dynamic temperature conditions.

The results from the experiments conducted with inoculated $\left(10^{3}\right.$ and $\left.10^{6} \mathrm{cfu} / \mathrm{g}\right)$ ice cream samples at constant freezing $\left(-5,-15,-23\right.$, and $\left.-33^{\circ} \mathrm{C}\right)$ conditions showed no significant changes in the population of $L$. monocytogenes during a storage period of $90 \mathrm{~d}$ for either inoculum level (Figure 5). These results are in agreement and further extend findings from previous studies on the survival of $L$. monocytogenes in contaminated ice cream during frozen storage. Palumbo and Williams (1991) have reported persistence of the pathogen for $14 \mathrm{wk}$ in ice cream stored at $-18^{\circ} \mathrm{C}$ with no apparent cell death or injury, whereas Dean and Zottola (1996) have reported constant $L$. monocytogenes counts in ice cream of 2 different milk fat levels throughout a 3 -mo frozen storage $\left(-18^{\circ} \mathrm{C}\right)$ study. Therefore, freezing storage cannot be used by the industry as a means of reducing the level of the pathogen in a contaminated batch.

Ideally, ice cream should be kept under constant freezing temperature conditions during its transporta-
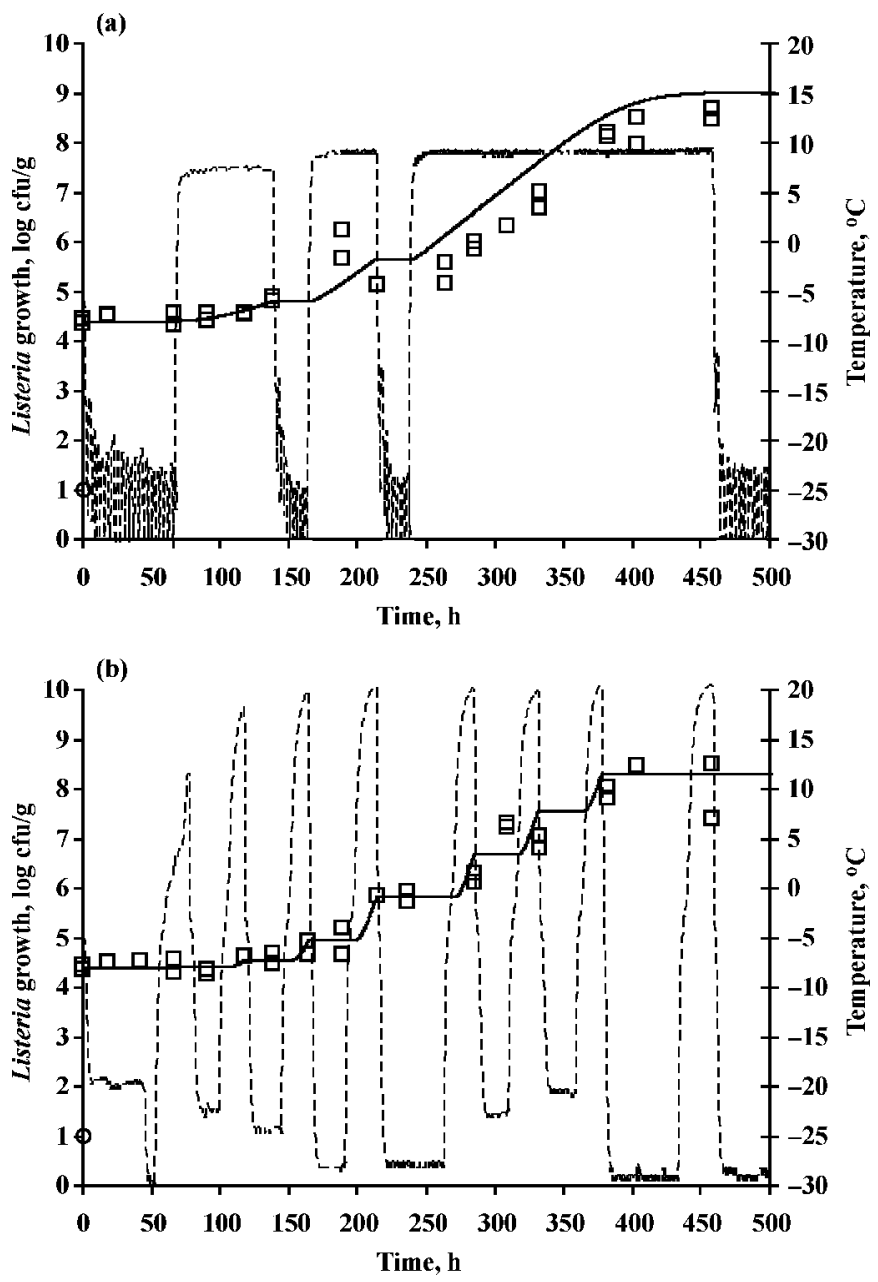

Figure 6. Comparison between observed (points) and predicted (lines) growth of Listeria monocytogenes in ice cream product A stored under 2 different dynamic chilling-freezing temperature profiles with random temperature fluctuations simulating temperature abuse during distribution and storage (a: profile A; b: profile B). Each point represents one replication from the same experiment.

tion and storage. However, the temperature conditions that prevail during the transportation of ice cream, as well as during its distribution and storage in retail, are beyond the direct control of the manufacturer and often deviate from the specifications set. In addition, there is no temperature control from the time ice cream is purchased from the retail store to the time of domestic storage and consumption. Indeed, an extensive survey in the United States showed that the temperature in $2.4 \%$ of retail ice cream products ranged between -3.3 and $2.2^{\circ} \mathrm{C}$ (Audits International, 2000). In the same survey, the temperature in $0.8 \%$ of domestic freezers was found to be higher than $0^{\circ} \mathrm{C}$. In the present study, the kinetic behavior of $L$. monocytogenes was also studied under dynamic freezing-chilling conditions, simulating temperature abuse during the transportation 


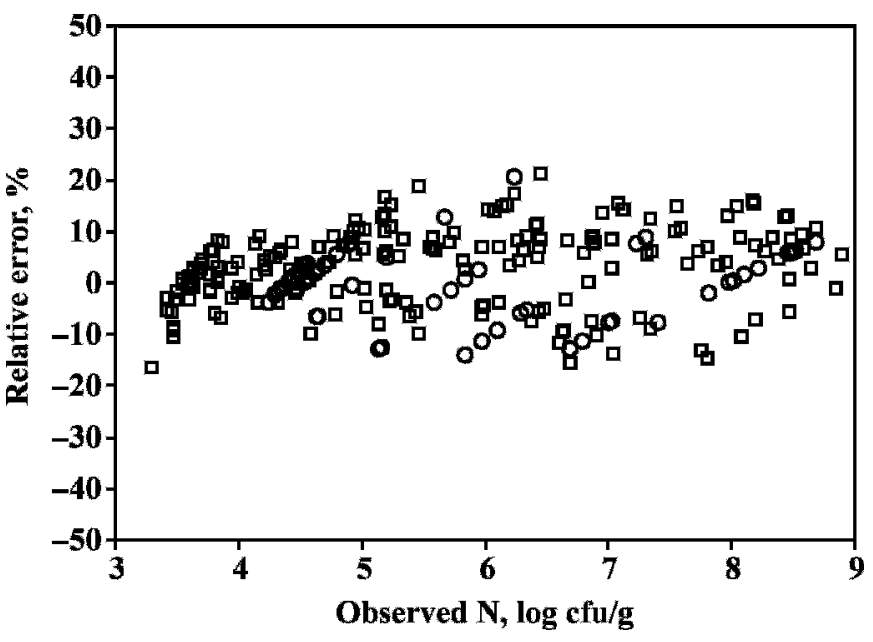

Figure 7. Percent relative errors $\left(\% \mathrm{RE}=\left[\left(\mathrm{n}_{\text {observed }}-\mathrm{n}_{\text {predicted }}\right) /\right.\right.$ $\left.\mathrm{n}_{\text {observed }}\right] \times 100, \mathrm{n}$ in log cfu/g) for the comparison between the observed and predicted growth of $L$. monocytogenes in ice cream stored under dynamic temperature conditions $(\square$ : dynamic chilling conditions, $\bigcirc$ : dynamic chilling-freezing conditions).

and storage of ice cream. The results from the chillingfreezing storage experiments showed that the pathogen is able to initiate growth after a temperature upshift from freezing to chilling temperatures within a very short time. This means that the stress imposed on $L$. monocytogenes cells by freezing conditions up to $-30^{\circ} \mathrm{C}$ is not severe enough to cause a significant "additional" lag phase during the subsequent growth of the pathogen at chilling conditions. Consequently, the application of the developed model to these conditions resulted in satisfactory results (Figure 6), with $98.3 \%$ of predictions lying within the $\pm 20 \% \mathrm{RE}$ zone (Figure 7). The abovementioned results are in contrast to those of Baranyi et al. (1995), who reported a significant overprediction of Brochothrix thermosphacta growth when the temperature profile contained step changes from 17 to $25^{\circ} \mathrm{C}$ down to the temperature limit for growth. In the latter study, the authors attributed this observation to the alteration of the physiological state of the organism caused by the sudden cold shock, which resulted in an additional lag phase. The fact that, in the present study, such an additional lag phase was not observed could be attributed to the relative low $a_{w}$ of the ice cream products, which may protect the pathogen from a severe cold shock.

In conclusion, the present study provides useful data for understanding the behavior of $L$. monocytogenes in ice cream stored under single or combined chilling and freezing conditions. In addition, such growth data can be expressed in quantitative terms via the application of mathematical models, which can be used by the dairy industry as effective tools for predicting the behavior of
L. monocytogenes during the manufacture, distribution, and storage of ice cream products.

\section{ACKNOWLEDGMENTS}

This work was conducted under the project "Total Microbial Safety in the Dairy Industry: Implementation of Modern and Quick Methods and Techniques for the Detection, Enumeration and Identification of Spoilage and Pathogenic Microorganisms-Modeling of Their Behavior Under the Usual Handling Procedures" (code TP5), which is co-funded $75 \%$ by the European Union and $25 \%$ by the Hellenic State, through Operational Programme Competitiveness.

\section{REFERENCES}

Alavi, S. H., V. M. Puri, S. J. Knabel, R. H. Mohtar, and R. C. Whiting. 1999. Development and validation of a dynamic growth model for Listeria monocytogenes in fluid whole milk. J. Food Prot. 62:170-176.

Audits International. 2000. 1999 U.S. Food Temperature Evaluation. Audits International and U.S. Food and Drug Administration. http://www.foodrisk.org/audits_international.htm Accessed Dec. $12,2006$.

Augustin, J.-C., V. Zuliani, M. Cornu, and L. Guillier. 2005. Growth rate and growth probability of Listeria monocytogenes in dairy, meat and seafood products in suboptimal conditions. J. Appl. Microbiol. 99:1019-1042.

Baek, S.-Y., S.-Y. Lim, D.-H. Lee, K.-H. Min, and C.-M. Kim. 2000. Incidence and characterization of Listeria monocytogenes from domestic and imported foods in Korea. J. Food Prot. 63:186-189.

Baranyi, J., and T. A. Roberts. 1994. A dynamic approach to predicting bacterial growth in food. Int. J. Food Microbiol. 23:277-294.

Baranyi, J., T. A. Robinson, A. Kaloti, and B. M. Mackey. 1995. Predicting growth of Brochothrix thermosphacta at changing temperature. Food Microbiol. 27:61-75.

Buchanan, R. L., and J. G. Phillips. 2000. Updated models for the effects of temperature, initial $\mathrm{pH}, \mathrm{NaCl}$ and $\mathrm{NaNO}_{2}$ on the aerobic and anaerobic growth of Listeria monocytogenes. Quant. Microbiol. 2:103-128.

Cordano, A. M., and J. Rocourt. 2001. Occurrence of Listeria monocytogenes in food in Chile. Int. J. Food Microbiol. 70:175-178.

Cotton, L. N., and C. H. White. 1992. Listeria monocytogenes, Yersinia eneterocolitica, and Salmonella in dairy plant environments. J. Dairy Sci. 75:51-57.

Dean, J. P., and E. A. Zottola. 1996. Use of nisin in ice cream and effect on the survival of Listeria monocytogenes. J. Food Prot. 59:476-480.

El-Sharef, N., K. S. Ghenghesh, Y. S. Abognah, S. O. Gnan, and A. Rahouma. 2006. Bacteriological quality of ice cream in TripoliLibya. Food Contr. 17:637-641.

European Commission. 2005. Commission Regulation (EC) No. 2073/ 2005 of 15 November 2005 on microbiological criteria for foodstuffs. 2005. Off. J. L 338:1-26.

Farber, J. M., Y. Cai, and W. H. Ross. 1996. Predictive modeling of the growth of Listeria monocytogenes in $\mathrm{CO}_{2}$ environments. Int. J. Food Microbiol. 32:133-144.

Farber, J. M., and P. I. Peterkin. 1991. Listeria monocytogenes, a food-borne pathogen. Microbiol. Rev. 55:476-511.

Fernández, P. S., S. M. George, C. C. Sills, and M. W. Peck. 1997. Predictive model of the effect of $\mathrm{CO}_{2}, \mathrm{pH}$, temperature and $\mathrm{NaCl}$ on the growth of Listeria monocytogenes. Int. J. Food Microbiol. 37:37-45.

George, S. M., L. C. C. Richardson, and M. W. Peck. 1996. Predictive models of the effect of temperature, $\mathrm{pH}$ and acetic and lactic acids 
on the growth of Listeria monocytogenes. Int. J. Food Microbiol. 32:73-90.

Greenwood, M. H., D. Roberts, and P. Burden. 1991. The occurrence of Listeria species in milk and dairy products: A national survey in England and Wales. Int. J. Food Microbiol. 12:197-206.

Kiss, R., T. Tirczka, G. Szita, S. Bernath, and G. Csiko. 2006. Listeria monocytogenes food monitoring data and incidence of human listeriosis in Hungary, 2004. Int. J. Food Microbiol. 112:71-74.

Kozak, J., T. Balmer, R. Byrne, and K. Fisher. 1996. Prevalence of Listeria monocytogenes in foods: Incidence in dairy products. Food Contr. 7:215-221.

Low, J. C., and W. Donachie. 1997. A review of Listeria monocytogenes and listeriosis. Vet. J. 153:9-29.

McClure, P. J., A. L. Beaumont, J. P. Sutherland, and T. A. Roberts. 1997. Predictive modelling of growth of Listeria monocytogenes. The effects on growth of $\mathrm{NaCl}, \mathrm{pH}$, storage temperature and $\mathrm{NaNO}_{2}$. Int. J. Food Microbiol. 34:221-232.

Meldrum, R. J., C. D. Ribeiro, R. M. M. Smith, A. M. Walker, M. Simmons, D. Worthington, and C. Edwards. 2005. Microbiological quality of ready-to-eat foods: Results from a long-term surveillance program (1995 through 2003). J. Food Prot. 68:1654-1658.

Miettinen, M. K., K. J. Bjorkroth, and H. L. Korkeala. 1999. Characterization of Listeria monocytogenes from an ice cream plant by serotyping and pulsed-field gel electrophoresis. Int. J. Food Microbiol. 46:187-192.

Molla, B., Y. Roman, and D. Alemayehu. 2004. Listeria monocytogenes and other Listeria species in retail meat and milk products in Addis Ababa, Ethiopia. Ethiop. J. Health Dev. 18:208-212.

Murphy, P. M., M. C. Rea, and D. Harrington. 1996. Development of a predictive model for growth of Listeria monocytogenes in a skim milk medium and validation studies in a range of dairy products. J. Appl. Bacteriol. 80:557-564.

Ng, D. L. K., and H. L. Seah. 1995. Isolation and identification of Listeria monocytogenes from a range of foods in Singapore. Food Contr. 6:171-173.
Pak, S.-I., U. Spahr, T. Jemmi, and M. D. Salman. 2002. Risk factors for $L$. monocytogenes contamination of dairy products in Switzerland, 1990-1999. Prev. Vet. Med. 53:55-65.

Palumbo, S. A., and A. C. Williams. 1991. Resistance of Listeria monocytogenes to freezing in foods. Food Microbiol. 8:63-68.

Pin, C., de F. G. García, J. A. Ordáñez, and J. Baranyi. 2002. Analysing the lag-growth rate relationship of Yersinia enterocolitica. Int. J. Food Microbiol. 73:197-201.

Pin, C., J. P. Sutherland, and J. Baranyi. 1999. Validating predictive models of food spoilage organisms. J. Appl. Microbiol. 87:491-499.

Ratkowsky, D. A., J. Olley, T. A. McMeekin, and A. Ball. 1982. Relationship between temperature and growth rate of bacterial cultures. J. Bacteriol. 149:1-5.

Ryser, E. T. 1999. Incidence and behaviour of Listeria monocytogenes in unfermented dairy products. Pages 359-409 in Listeria, Listeriosis, and Food Safety. 2nd ed. E. T. Ryser and E. H. Marth, ed. Marcel Dekker Inc., New York, NY.

Schlech, W. F., III, P. M. Lavigne, R. A. Bortolussi, A. C. Allen, E. V. Haldane, A. J. Wort, A. W. Hightower, S. E. Johnson, S. H. King, E. S. Nicholls, and C. V. Broome. 1983. Epidemic listeriosis-Evidence for transmission by food. N. Engl. J. Med. 308:203-206.

Stopforth, J. D., P. N. Skandamis, J. N. Sofos, and P. M. Davidson. 2005. Naturally occurring compounds-Animal sources. Pages 453-506 in Antimicrobials in Food. 3rd ed. P. M. Davidson, J. N. Sofos, and A. L. Branen, ed. CRC Press, Boca Raton, FL.

te Giffel, M. C., and M. H. Zwietering. 1999. Validation of predictive models describing the growth of Listeria monocytogenes. Int. J. Food Microbiol. 46:135-149.

Walker, R. L., L. H. Jensen, H. Kinde, A. V. Alexander, and L. S. Owens. 1991. Environmental survey for Listeria species in frozen milk product plants in California. J. Food Prot. 54:178-182.

Xanthiakos, K., D. Simos, A. S. Angelidis, G. J.-E. Nychas, and K. Koutsoumanis. 2006. Dynamic modeling of Listeria monocytogenes growth in pasteurised milk. J. Appl. Microbiol. 100:1289-1298. 